\title{
3 Modelling Gene-Environment Interactions in Th1- and Th2-Dominated Diseases of Laboratory Animals
}

G. A. W. Rook, R. Martinelli, L. Rosa Brunet

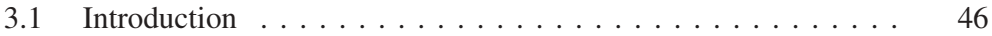

3.2 The Hygiene Hypothesis . . . . . . . . . . . . . . . 46

3.2.1 Findings That Undermined the Early Rationalisation of the Hygiene Hypothesis . . . . . . . . . . . . . . . . 47

3.2.2 Does Th1/Th2 Balance Play a Role? . . . . . . . . . . . . 49

3.2.3 Imbalance Between Effector $\left(\mathrm{T}_{\text {eff }}\right)$ and Regulatory $\mathrm{T}$ Cells $\left(\mathrm{T}_{\mathrm{reg}}\right)$ : Lessons from Foxp3 . . . . . . . . . . . . . . . 49

3.3 The "Old Friends" Hypothesis . . . . . . . . . . . . . . 50

3.3.1 Experimental Evidence for the Induction of Allergen-Specific $\mathrm{T}_{\text {reg }}$ by "Old Friends" . . . . . . . . . . . . . . . 52

3.3.2 The Physiological Role of Bystander Suppression . . . . . . 52

3.3.3 $\mathrm{T}_{\text {reg }}$ May Not Suppress When the Innate Immune System Detects "Danger" . . . . . . . . . . . . . . . 53

3.4 Innate Immunity and Induction of $\mathrm{T}_{\mathrm{reg}} \ldots \ldots \ldots \ldots \ldots .53$

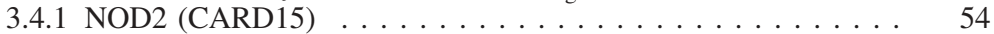

3.4 .2 Toll-Like Receptors . . . . . . . . . . . . . . . . . 54

3.4.3 TLR and Susceptibility to Disorders of Immunoregulation ... 54

3.4.4 Toll-Like Receptors and $\mathrm{T}_{\mathrm{reg}} \ldots \ldots \ldots \ldots \ldots \ldots \ldots \ldots$

3.4.5 CD14 and Inflammatory Disorders $\ldots \ldots \ldots \ldots \ldots \ldots .56$

3.4.6 NRAMP1 (SLc11a1) in Diseases of Immunodysregulation . . . 56

3.4.7 CD1-Restricted T Cells . . . . . . . . . . . . . . . . 57

3.4.8 Immunoregulatory Cytokines . . . . . . . . . . . . . 57

3.5 Animal Models for Studying Interactions Between Genes and Commensal or Environmental Microorganisms . . . . . 58

3.5.1 Models of Inflammatory Bowel Disease and Microbial Exposure

\section{Zollner}

(3B2 - Version 6.0 - Englisch) 
3.5.2 Models of Allergic Disorders and Microbial Exposure ... . . 59

3.5.3 Models of Autoimmune Disease and Microbial Exposure ... $\quad 59$

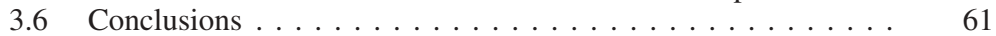

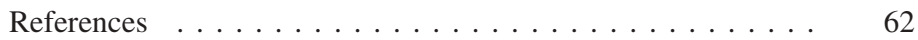

\subsection{Introduction}

Several types of chronic inflammatory disorder are becoming much more common in the rich developed countries. These include inflammatory bowel diseases (IBD) such as ulcerative colitis, and Crohn's disease, certain autoimmune diseases (type 1 diabetes and multiple sclerosis) and allergies. The latter includes atopic dermatitis, clearly of interest to this symposium which is focused on skin disease. It will be argued below that the rapidly increasing prevalence of these disorders can be attributed to changing patterns of microbial exposure in modern life, leading to a failure of immunoregulatory mechanisms in individuals with certain genetic polymorphisms of the innate immune system. This view is referred to as the "Old Friends" hypothesis, and is an updating of the previous "Hygiene Hypothesis". In addition, this chapter will include discussion of certain aspects of psoriasis, because although it is unclear whether its prevalence is increasing in developed countries, psoriasis has some epidemiological association with diseases which are increasing in prevalence (such as Crohn's disease; Najarian and Gottlieb 2003) and shows signs of immunoregulatory dysfunction, such as excessive Th1 activity and IL-10 deficiency.

\subsection{The Hygiene Hypothesis}

The "Hygiene Hypothesis" as it exists in 2003 is very different from the hypothesis that emerged in the late 1990s. By that time, the view that changing patterns of infectious disease might lead to changes in the incidence or presentation of various immunological disorders had appeared intermittently in the medical literature for decades. In 1996 Strachan and colleagues, who were interested in the striking increase in the prevalence of allergic disorders in the developed coun- 
tries, gave a new impetus to the idea when they observed that allergies were less common in children from large families with older siblings, especially older brothers (Strachan et al. 1996). A flood of further epidemiological data, particularly studies of farming communities (Braun-Fahrlander et al. 2002; Riedler et al. 2001) and military personnel (Matricardi et al. 2000) provided circumstantial support for the view that diminished exposure to certain microorganisms might lead to an enhanced risk of allergy.

\subsubsection{Findings That Undermined the Early Rationalisation of the Hygiene Hypothesis}

Most authors treated the Hygiene Hypothesis as though it was synonymous with a "Th1/Th2 see-saw hypothesis". In other words it was suggested that Th1 responses are needed to downregulate Th2 responses, and that the hygienic conditions of modern life provide too little stimulus for Th1 cells, with a consequent non-specific increase in Th2 activity. With hindsight it is clear that this view was deeply flawed. First, Th1 responses are not physiological regulators of Th2 activity. Indeed individuals with an almost complete lack of Th1 responses due to congenitally defective IFN $-\gamma$ receptors do not have increased Th2 activity (Lammas et al. 2000). The earlier literature suggesting that in vivo Th1 cells downregulate Th2 responses must be re-interpreted in the light of the existence of distinct subsets of regulatory $T$ cells $\left(T_{\text {reg }}\right)$. When the presence of $T_{\text {reg }}$ is rigorously excluded and cloned polarised Th1 cells are used in cell transfer experiments, Th1 cells may even exacerbate ongoing Th2-mediated inflammation (Hansen et al. 1999). Indeed, synergy between Th1 and Th2 cells is emerging as a major mechanism of severe immunopathology in some infections (Hernandez-Pando et al. 2003), and it is often forgotten that IFN- $\gamma$ is in fact a dominant cytokine in human asthma (Krug et al. 1996).

The death blow to the "Th1/Th2 see-saw" interpretation was the realisation that countries experiencing increased incidences of these Th2-mediated disorders were simultaneously experiencing parallel increases in Th1-mediated autoimmune disorders and IBD (Rook 2000). Thus there is a striking correlation between Type 1 diabetes 


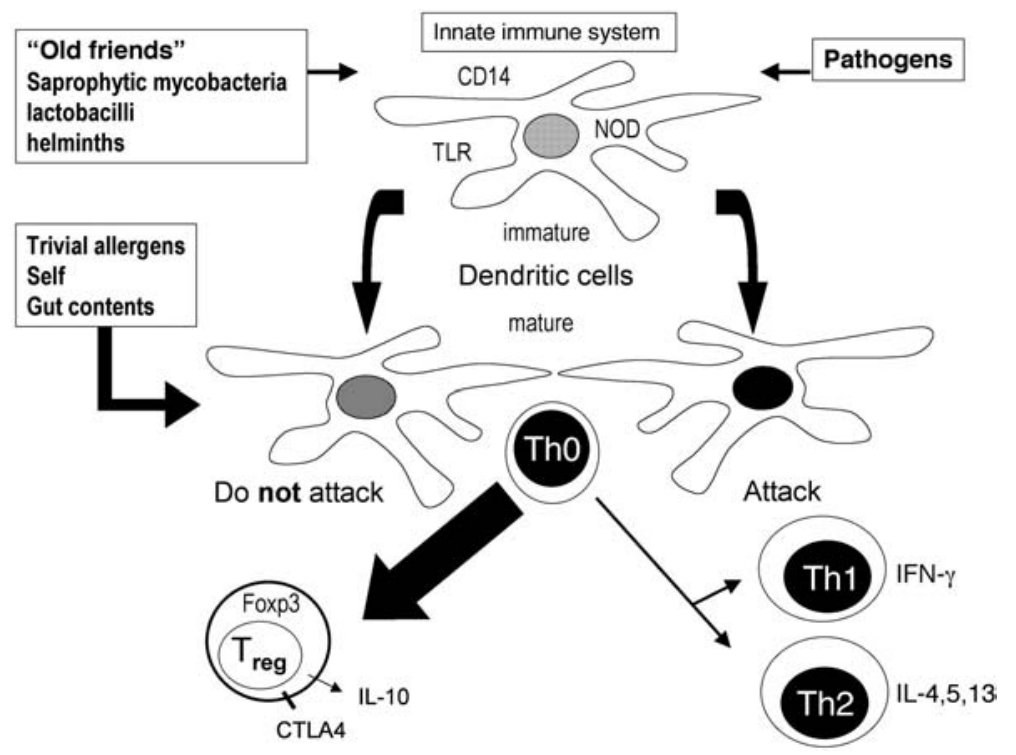

Fig. 1. The "old friends" hypothesis. A cartoon of mechanisms that might explain the links between patterns of microbial exposure and susceptibility to disorders of immunoregulation in man and animals. The "old friends" (harmless organisms that have been interacting with the mammalian immune system throughout our evolutionary history) are recognised by components of the innate immune system (including CD14, Toll-like receptors (TLRs), and NOD1 and NOD2) in such a way that DCs mature to a phenotype that drives formation of regulatory $\mathrm{T}$ cells $\left(\mathrm{T}_{\mathrm{reg}}\right)$. Pathogens, on the other hand, drive maturation of DC that activate Th1 or Th2 effector mechanisms. Some, perhaps all $\mathrm{T}_{\text {reg }}$ express the transcription factor Foxp3, and often CTLA-4 and IL-10. Because the "old friends" cause maturation of DC that drive regulation, they act as adjuvants for the development of regulatory cells that recognise other harmless antigens processed by the same DC, such as self, allergens, and gut contents. Polymorphisms within the innate immune system result in altered efficiency of $\mathrm{T}_{\text {reg }}$ induction, and so may lead to increased susceptibility to allergies, autoimmunity, or IBD

(Th1-mediated destruction of $\beta$ cells in the pancreas) and allergies, both within and outside Europe (Stene and Nafstad 2001). Similarly, IBD is increasing in the same countries (Lindberg et al. 2000; Sawczenko et al. 2001). These parallels have been extensively reviewed (Bach 2002). Clearly the explanation for the increased prevalence of 
allergic disorders cannot be a lack of stimuli for Th1 activity if Th1mediated diseases are also increasing. We are witnessing a simultaneous increase in both Th1 and Th2 immune responses against targets that should be tolerated, such as trivial levels of allergens, self, and the contents of the gut, leading to allergies, autoimmunity, and IBD respectively. The current hypothesis (expanded in detail later) is that the balance of regulatory $T$ cells $\left(T_{\text {reg }}\right)$ to effector $T$ cells $\left(T_{\text {eff }}\right)$, whether Th1 or Th2, is more important than the balance of Th1 to Th2 cells (Fig. 1).

\subsubsection{Does Th1/Th2 Balance Play a Role?}

Although Th1-mediated and Th2-mediated inflammatory disorders are increasing in parallel within populations (Bach 2002; Stene and Nafstad 2001), there does seem to be some segregation of Th1 and $\mathrm{Th} 2$ at the level of the individual in some studies. For example, people suffering from the Th1-mediated autoimmune diseases, type 1 diabetes or multiple sclerosis, are less likely to be allergic (Douek et al. 1999; Tremlett et al. 2002). However, the Th1/Th2 balance of the individual might reflect genetic background and past history of infections and vaccinations. This in turn might determine the type of disorder of immunoregulation that will occur in that individual when $\mathrm{T}_{\text {reg }}$ activity is compromised. Psoriasis is interesting in this context. A recent report suggests that this condition can be treated with IL-4, in which case this Th1-mediated disease at least can be modulated by a Th2 cytokine (Ghoreschi et al. 2003). So although there is good evidence that Th1 activity is not a physiological regulator of Th2 cells (Lammas et al. 2000), it remains possible that Th2 activity can sometime modulate Th1 responses. However, it must not be forgotten that some $\mathrm{T}_{\text {reg }}$ express IL-4 (Seddon and Mason 1999).

\subsubsection{Imbalance Between Effector ( $T_{\text {eff }}$ ) and Regulatory $T$ Cells $\left(\mathrm{T}_{\text {reg }}\right)$ : Lessons from Foxp3}

The ability of decreased activity of $\mathrm{T}_{\text {reg }}$ to explain the simultaneous increases in all three major groups of immunoregulatory disorder has 
now been repeatedly reviewed (Rook and Brunet 2002; Umetsu et al. 2002; Yazdanbakhsh et al. 2002). Support for this view has come from recent analyses of genetic disorders of human and mouse attributable to mutations in the transcription factor Foxp3 (Brunkow et al. 2001; Wildin et al. 2001). Foxp3 is fundamental to the development of $\mathrm{T}_{\text {reg }}$ (Fontenot et al. 2003; Hori et al. 2003). In both species the resulting pathology encompasses precisely the spectrum of diseases (allergies, autoimmunity, and IBD) that is increasing in the developed world.

\subsection{The "Old Friends" Hypothesis}

But why should diminished exposure to microorganisms result in inadequate priming of $\mathrm{T}_{\text {reg }}$ ? In fact, $\mathrm{T}_{\text {reg }}$ are probably part of the normal immune response to pathogens. After the effector response has reduced pathogen numbers to low levels, $T_{\text {reg }}$ may help to terminate the response and allow for the development of concomitant immunity (Belkaid et al. 2002). But clearly, excessive early activation of $\mathrm{T}_{\text {reg }}$ by pathogens would lead to progressive disease. Therefore the organisms most likely do have a highly developed ability to drive $\mathrm{T}_{\text {reg }}$ rather than $\mathrm{T}_{\text {eff }}$, and perhaps to bypass the phase of $\mathrm{T}_{\text {eff }}$ induction altogether (Schultz et al. 2002), are harmless "old friends" and commensals that have been present throughout our evolutionary history, and that have become part of mammalian physiology. In addition to the unidentified (but clearly non-pathogenic) factor present in German cowsheds (Riedler et al. 2001), four groups of organism have been highlighted in this context; lactobacilli (Kalliomaki and Isolauri 2003), saprophytic environmental mycobacteria (Rook and Stanford 1998; Zuany-Amorim et al. 2002), helminths (Yazdanbakhsh et al. 2002), and certain viruses that are ubiquitous in developing countries (McIntire et al. 2001).

Lactobacilli were an integral part of the hunter-gatherer diet, and were common in poorly preserved vegetables and in beverages prepared by malo-lactic fermentation (Kalliomaki and Isolauri 2003). Interestingly lactobacilli are present in greater quantities in the guts of children from areas with a low incidence of allergies (Sepp et al. 1997). Similarly the saprophytic mycobacteria are ubiquitous in mud 
and untreated water, and used to be consumed in such quantities that detectable levels of tuberculostearic acid accumulated in lymphoid tissue (Hanngren et al. 1987). The presence of mycobacteria in the mammalian evolutionary past is indicated by the presence of CD1restricted T-cell subsets that appear to recognise only mycobacterial lipids and glycolipids (Dutronc and Porcelli 2002). Exposure remains high in developing countries, where most of the population has skin-test positivity to multiple mycobacterial species (Stanford et al. 1981). In contrast, this is rare in the rich countries. Helminths are endemic in developing countries, and cause little or no pathology in the majority of infected individuals. This is achieved by the induction of $T_{\text {reg. }}$. Indeed, the ability of helminths to drive $T_{\text {reg }}$ activity is an integral component of the host-parasite relationship. When this mechanism fails, an exaggerated immune response to the parasite ensues, with massive lymphadenopathy and pathology (Satoguina et al. 2002; Steel and Nutman 2003). Virus infections characteristic of childhood in the developed countries appear not to protect from allergies (Matricardi et al. 2000), which fits with the fact that children in inner cities are heavily exposed to these infections and still have a high and rising risk of allergies. However, antibody to infections transmitted by the faeco-oral route correlated with a lower incidence of allergic symptoms (Matricardi et al. 2000). Subsequently it has emerged that a T-cell membrane protein, TIM-1, that controls the development of airway hyperreactivity and production of Th2 cytokines in mice is a homologue of the human hepatitis A virus (HAV) receptor, which may explain the inverse relationship between HAV infection and the development of atopy (McIntire et al. 2001).

Each of these groups of organism has been implicated in downregulation of allergic responses in humans, either by direct clinical studies or (less convincingly) by epidemiological correlation (Arkwright and David 2001; Camporota et al. 2003; Kalliomaki et al. 2001; Matricardi et al. 2000; van den Biggelaar et al. 2000). Moreover, components of Schistosoma mansoni (helminth) and Mycobacterium vaccae (saprophytic environmental mycobacterium) have been shown to induce $T_{\text {reg }}$ in vitro (van der Kleij et al. 2002) and in vivo, respectively (Zuany-Amorim et al. 2002). 


\subsubsection{Experimental Evidence for the Induction of Allergen-Specific $T_{\text {reg }}$ by "Old Friends"}

A GMP preparation of $M$. vaccae, which has been used in clinical trials, has been shown experimentally to induce $\mathrm{T}_{\text {reg }}$ (Zuany-Amorim et al. 2002). The specificity of the $T_{\text {reg }}$ induced was tested in a cell transfer system. It was demonstrated that the $T_{\text {reg }}$ induced have specificity for the allergen to which the animals were exposed, but that once the regulatory properties of the $T_{\text {reg }}$ have been triggered they can exert bystander inhibition on the response to other allergens (Zuany-Amorim et al. 2002).

\subsubsection{The Physiological Role of Bystander Suppression}

This bystander phenomenon may be of fundamental importance to immunoregulatory disorders. When SCID mice (which lack T lymphocytes) were reconstituted with $\mathrm{T}_{\text {eff }}$ with a normal range of specificities, they developed severe colitis. The colitis persisted if they were given cloned transgenic $T_{\text {reg }}$ specific for a single epitope of ovalbumin. However if ovalbumin was added to the diet, the bystander suppression exerted by the ovalbumin-specific $T_{\text {reg }}$ was able to alleviate the colitis, despite the fact that the colitis will have been triggered by multiple antigens within the food and gut flora (Groux et al. 1997). These observations emphasise the point that the "old friends" discussed earlier may have two distinct roles. Experiments in vitro and in vivo suggest that they can act as " $\mathrm{T}_{\text {reg }}$ adjuvants", maturing antigen-presenting cells (APCs) to a phenotype that tends to direct $\mathrm{T}$ cells towards specific regulatory function (van der Kleij et al. 2002; Zuany-Amorim et al. 2002). However the "old friends" may also provide a crucial background of regulation, because their constant presence leads to a steady background activation of $\mathrm{T}_{\text {reg }}$ that recognise the "old friends" themselves. Again this argument points towards organisms that will have been taken in orally throughout mammalian evolution (such as saprophytic mycobacteria and lactobacilli) and organisms that were permanently present in the tissues (such as helminths). 


\subsection{3 $\mathrm{T}_{\text {reg }}$ May Not Suppress When the Innate Immune System Detects "Danger"}

Why does bystander suppression not constantly incapacitate the immune system? Conceptually the answer must be that $\mathrm{T}_{\text {reg }}$ downregulate immune responses that should not be there, such as responses to self, gut contents, and trivial levels of harmless allergens. But when "danger signals" are present, the $\mathrm{T}_{\text {reg }}$ must stop regulating and allow full immune responses. In an in vitro system, $\mathrm{T}_{\text {reg }}$ failed to function when danger signals were provided by addition of $\mathrm{CpG}$ motifs or endotoxin (Pasare and Medzhitov 2003). Similarly, $T_{\text {reg }}$ can block graft-versus-host disease while permitting anti-tumour responses (Edinger et al. 2003). Finally, it has been noted that $T_{\text {reg }}$ express an unusual pattern of Toll-like receptors (TLRs), and these may also play a role in the modulation of their function (Caramalho et al. 2003).

\subsection{Innate Immunity and Induction of $\mathbf{T}_{\text {reg }}$}

How then are the "old friends" recognised as harmless, and how does that recognition lead to the activation of $\mathrm{T}_{\text {reg }}$ ? Similarly, how do danger signals sometimes stop $\mathrm{T}_{\text {reg }}$ from developing, as outlined in the previous paragraph? The answer probably lies in the innate immune system. The pattern recognition receptors (PRRs) of the innate immune system recognise pathogen-associated molecular patterns (PAMPs). (The use of the word "pathogen" here is misleading since these receptors are also involved in recognition of commensals and even of self components such as heat-shock proteins (HSPs)). The PRRs then drive rapid protective mechanisms before the adaptive response can be generated, and then direct the adaptive response towards appropriate attack mechanisms or towards immunoregulation. It is therefore of particular interest that polymorphisms of genes involved in the innate immune system are proving to be relevant to the incidence of immunoregulatory disorders. The parallels between the components of the innate immune system that are involved in recognition of bacteria and the components that have been shown to be relevant to the allergies have been reviewed elsewhere (Rook et al. 2003). A few examples are given below. 


\subsubsection{NOD2 (CARD15)}

Bacterial cell wall muramyl peptides can signal via recently discovered intracellular PRRs of the innate immune system, NOD1 (CARD4) and NOD2 (CARD15). Interestingly, polymorphisms of NOD2 are associated both with susceptibility to Crohn's disease, a predominantly Th1-mediated condition (Ogura et al. 2001) and also to allergies, a Th2-mediated condition (Kabesch et al. 2003). Similarly, in patients from Newfoundland, polymorphisms of NOD2 were associated with susceptibility to psoriasis that was independent of HLA-Cw*0602, so NOD2 may be the first non-MHC gene to be associated with psoriasis (Rahman et al. 2003). These are therefore examples of genetically impaired recognition of bacterial components leading to a variety of Th1-mediated or Th2-mediated immunoregulatory disorders in different individuals.

\subsubsection{Toll-Like Receptors}

Ten Toll-like receptor (TLR) types are known, and these may act as homo- or heterodimers with other TLR. They are PRRs that bind conserved microbial derivatives such as LPS, lipoproteins, peptidoglycans, glycosylphosphatidylinositols, double-stranded RNA, CpG motifs in DNA, and flagellin. All microorganisms contain ligands for many TLRs. Nevertheless when whole live organisms are added to TLR-expressing cells, a more restricted pattern can emerge. For example, Gram-negative bacteria tend to trigger TLR4, whereas mycobacteria tend to trigger TLR2 (Heldwein and Fenton 2002).

\subsubsection{TLR and Susceptibility to Disorders of Immunoregulation}

Recent data suggest the possibility of links between polymorphisms of TLR-2 and susceptibility to asthma. Exposure to the farming environment during early life significantly protects from allergic disorders (Riedler et al. 2001), and this beneficial effect is dependent upon a polymorphism of TLR-2. Blood cells from the children from these farms express significantly higher amounts of mRNA encoding 
CD14 and TLR2 (but not TLR4) than do those from non-farmers' children (Lauener et al. 2002). Currently TLR-4, which is triggered by LPS, looks less interesting. LPS, which is stable, and easily assayed in the environment and bedding, may represent a stable marker for microbial exposure in the farming environment (Braun-Fahrlander et al. 2002). One recent study found no evidence that genetic variation in TLR4 contributes to asthma susceptibility (Raby et al. 2002).

Striking changes in the expression of TLRs and CD91 (a receptor for HSPs) have been observed in psoriatic skin, but we are not aware of any evidence that polymorphisms of these molecules alter susceptibility to the condition (Baker et al. 2003; Curry et al. 2003).

\subsubsection{Toll-Like Receptors and $T_{\text {reg }}$}

Activation of human dendritic cells (DCs) via TLR4 and TLR2 may result in different immunological outcomes (Re and Strominger 2001). Unlike TLR4, TLR2 does not lead to release of IL-12 but rather of inhibitory IL-12 p40 dimers (O'Neill 2002) and IL-23, which is formed when $\mathrm{p} 40$ dimerises with $\mathrm{p} 19$. IL-23 has a different spectrum of activities from IL-12, and unlike IL-12, causes proliferation of murine $C D 45 R^{\text {low }} \mathrm{T}$ cells, that might include $\mathrm{T}_{\text {reg }}$ (Oppmann et al. 2000). Human DCs pre-incubated with a schistosomal extract caused T cells to secrete IL-10 (Van der Kleij et al. 2002). However, if TLR2 was blocked with an antibody, the $\mathrm{T}$ cells secreted Th2 cytokines, but no IL-10 (Van der Kleij et al. 2002). Heat-shock proteins can also trigger TLR, including TLR2 (Asea et al. 2002; Bulut et al. 2002), and can drive $\mathrm{T}_{\text {reg }}$ (van Eden et al. 2003).

It is not yet clear why the same TLR can sometimes drive potent inflammatory responses, and yet be essential for initiating regulation. As stated above, the anti-inflammatory effects of lactobacilli require TLR9, but there is nothing special about their DNA. It seems that the lactobacilli present their DNA in a "package", or in the context of other signals to the innate immune system, that permit their recognition as "old friends", and consequently allow the activation of regulation (Rachmilewitz et al. 2002). Such findings imply that 
mimicking the effects of the "old friends" with single molecules may be difficult. The "code" for $\mathrm{T}_{\text {reg }}$ induction is likely to be complex so that pathogens do not too easily acquire it.

\subsubsection{CD14 and Inflammatory Disorders}

CD14 is expressed by myeloid cells, and secreted by them, and by the liver. It is not a signalling molecule, but it plays a crucial role in binding many microbial components (notably LPS and LAM) and facilitating their interaction with cell membrane-associated signalling molecules such as TLR. A polymorphism in the promoter region of the CD14 gene controls CD14 expression on monocytes and sCD14 levels in the sera of healthy subjects. In some studies of allergic individuals (Baldini et al. 1999) but not others (Sengler et al. 2003), such polymorphisms correlate to the levels of circulating IgE. Low CD14 in amniotic fluid or breast milk has been associated with increased risk of atopic eczema and of allergic sensitisation (Jones et al. 2002). The blood cells of children of farmers, who have a reduced risk of allergies associated with their exposure to the farming environment, expressed higher levels of mRNA encoding CD14 (Lauener et al. 2002).

CD14 has also attracted interest in relation to psoriasis. Keratinocytes of psoriatic skin express membrane-bound CD14 (mCD14), and soluble CD14 (sCD14) is elevated in the sera of psoriatic patients. However, a study of 63 Finnish patients with psoriasis and 126 non-psoriatic controls suggested that the enhanced CD14 expression in psoriasis is not attributable to functional variants of CD14 (Karhukorpi et al. 2002).

\subsubsection{NRAMP1 (SLc11a1) in Diseases of Immunodysregulation}

The Nramp1 gene was originally described as Ity/Lsh/Bcg, a gene controlling an early phase of resistance of inbred mice to intramacrophage pathogens. Stratification by BCG vaccination unmasked a potential genetic risk factor for atopy in the region of the Slc11a1 locus (Alm et al. 2002). Moreover IBD, multiple sclerosis, and rheu- 
matoid arthritis have been associated with various polymorphisms (Kojima et al. 2001; Kotze et al. 2001; Rodriguez et al. 2002). Similarly, in a mouse model of allergy induced by immunisation with ovalbumin in alum, Nramp $1^{\mathrm{r}}$ animals showed less release of Th2 cytokines, IgE, and mast cell granules into the airways after aerosol challenge compared to congenic Nramp1 ${ }^{\mathrm{s}}$ mice (Smit et al. 2003). We are unaware of any studies of Slc11a1 in psoriasis.

\subsubsection{CD1-Restricted T Cells}

A major component of the early response to microorganisms (in particular mycobacteria) is mediated by CD1-restricted $\mathrm{T}$ cells and NKT cells (Dutronc and Porcelli 2002). CD1c-restricted T cells play an important role in the early maturation of DCs, and in driving the DC phenotype towards one that will encourage development of Th1 responses (Vincent et al. 2002). Ligands that interact with CD1 would be expected to modulate this process. CD1-restricted cells recognising glycolipid antigens might be involved in psoriasis (Nickoloff 1999). Interestingly, airway challenge with house dust mite causes a striking influx of CD1c + DC into the airways of asthmatics (Jahnsen et al. 2001).

\subsubsection{Immunoregulatory Cytokines}

There have been numerous studies of polymorphisms of cytokines and their receptors. We will only consider IL-10 as it is involved in immunoregulation. Monocytes from severe asthmatics secrete less IL-10 (Tomita et al. 2002), and a haplotype associated with low IL10 production occurs in patients with severe asthma (Lim et al. 1998). Similarly it has been suggested that differences in the IL-10 secretion levels due to polymorphisms might contribute to the differences in the clinical course or time of presentation of psoriasis (Hensen et al. 2003; Kingo et al. 2003). IL-10 has shown potential in the treatment of psoriasis (Asadullah et al. 2003). 


\subsection{Animal Models for Studying Interactions Between Genes and Commensal or Environmental Microorganisms}

The preceding discussion points to the need for animal models that can be used to study the effects of varying the microbial input, and the dependence of such effects on polymorphisms within the innate immune system. Some of the work indicating the effects of the microbial environment will be outlined in the following sections, and where this has been looked at in relation to the innate immune system, this will be indicated.

\subsubsection{Models of Inflammatory Bowel Disease and Microbial Exposure}

Interleukin 10-deficient (IL-10 ${ }^{-/-}$) mice remain healthy under germfree conditions, but some IL-10-deficient strains develop colitis when given a normal specific pathogen-free (SPF) bowel flora. This is due to a poorly controlled immune response to the bowel flora. Interestingly, colonisation of germ-free IL- $10^{-/-}$mice with Lactobacillus plantarum does not induce colitis, and can protect from subsequent introduction of SPF flora. Moreover L. plantarum also alleviates the established colitis in SPF IL- $10^{-1-}$ mice (Schultz et al. 2002). These protective effects may depend upon TLR9, which binds CpG motifs (Rachmilewitz et al. 2002). Similarly, antigen preparations from anaerobic bowel commensals given by gavage to $\mathrm{Balb} / \mathrm{c}$ mice alleviate colitis induced by dextran sulphate, which is also attributable to an immune response to gut contents (Verdu et al. 2000). Interestingly, the colitis seen in SPF $\mathrm{IL}-2^{-/-}$mice also depends upon the presence of intestinal bacterial flora (Contractor et al. 1998).

HLA-B27 transgenic rats provide another model. Normal luminal bacteria play an essential role in initiating and perpetuating the chronic colitis, gastritis, and joint disease in these animals (Rath 2002), though the skin and genital inflammatory lesions are unaffected by the germ-free state. Obligate anaerobic bacteria, especially Bacteroides species, may play a predominant role, since metronidazole prevents colitis (Rath 2002). 


\subsubsection{Models of Allergic Disorders and Microbial Exposure}

A number of observations suggest a role for commensal intestinal flora in allergic disorders. For example, in germ-free mice IgE production cannot be switched off by orally induced tolerance (Sudo et al. 1997). Similarly, neonatal antibiotic treatment can deviate the immune system towards Th2. These effects are prevented if commensal intestinal flora are re-introduced (Sudo et al. 1997, 2002). Such observations imply a role for $\mathrm{T}_{\text {reg }}$ induction in the gut in these animal models of allergy. It was recently proved that a preparation of an environmental saprophytic mycobacterium can induce allergen-specific $\mathrm{T}_{\text {reg }}\left(\mathrm{CD} 4^{+}, \mathrm{CD}_{4} 5 \mathrm{RB}^{\text {low }}, \mathrm{IL}-10^{+}\right)$that not only inhibit allergic symptoms, but are also active in a passive transfer model. Their function in the allergic recipient animals was blocked by a combination of anti-IL-10 and anti-TGF- $\beta$ (Zuany-Amorim et al. 2002a,b). The same material is active via the oral route, though it has not been formally shown that the material acts via induction of $\mathrm{T}_{\text {reg }}$ when used in this way (Laura Rosa Brunet, Jon Hunt, and Graham Rook; unpublished observations).

Another model is provided by the DS-Nh (DS $\mathrm{Nh} /{ }^{+}$) mouse. These animals develop dermatitis spontaneously when they are housed in a conventional environment. When they are raised under SPF conditions, similar clinical and histopathological symptoms were inducible with repeated percutaneous immunisation of heatkilled Staphylococcus aureus on the back (Hikita et al. 2002). The dermatitis can occur in the absence of $S$. aureus, but is less severe (Watanabe et al. 2003). There are likely to be complex interactions between the gut flora (absent/SPF/normal), and the presence or absence of the inducing organism ( $S$. aureus), and polymorphisms within the innate immune system.

\subsubsection{Models of Autoimmune Disease and Microbial Exposure}

Not all models of autoimmune disease are influenced by microbial flora, but many are. For instance, non-obese diabetic (NOD) mice reared in gnotobiotic environments have worsened diabetes (Kukreja and Maclaren 2002). Similarly, female PVG/c strain rats maintained 
under specific pathogen-free conditions until weaning were found to be significantly less susceptible to the induction of autoimmune thyroiditis by thymectomy and irradiation than conventionally reared rats of the same strain (Penhale and Young 1988). However the most striking effects are seen in various models of autoimmune arthritis. Although the mechanisms were not understood, it was known in the 1980 s that germ-free rats were moderately susceptible to adjuvant arthritis, and that this susceptibility could be enhanced or decreased simply by reconstituting the bowel flora with different bacterial species (Kohashi et al. 1985). Thus, bacterial flora can influence susceptibility to arthritis either way, causing either exacerbation or attenuation of disease. This variability may highlight the need to distinguish between "old friends" that are inducing immunoregulation, and "triggering" organisms that induce disease in appropriate hosts either as target antigens, or as a result of some critical cross-reactivity. Susceptibility to pristine-induced arthritis, which involves immune responses to hsp60, requires exposure to other arthritic animals, presumably to something present within their microbial flora (Thompson and Elson 1993). Similarly, neither the ankylosing enthesopathy in B10.BR mice (Rehakova et al. 2000) nor the inflammatory peripheral joint disease of HLA-B27 transgenic rats will occur if the animals are raised in a germ-free environment (Taurog et al. 1994).

The previous paragraph describes models in which the microbial flora exacerbate the arthritis, but in general the bacterial flora appear to protect. For example, collagen-induced arthritis is increased in germ-free DA rats compared to conventionally raised rats (Breban et al. 1993). Similarly, germ-free Wistar rats are much more susceptible to adjuvant arthritis than are conventionally raised Wistar rats (van de Langerijt et al. 1994). Moreover, transfer of spleen cells from the "dirty" rats to the clean rats is sufficient to reduce the susceptibility of the latter (Moudgil et al. 2001). Thus in various rat strains, background exposure to harmless microorganisms can influence Th1-mediated autoimmunity, and the last experiment quoted suggests a role for $\mathrm{T}_{\text {reg. }}$. The mechanism has been studied further in streptococcal cell wall arthritis. This is a chronic, erosive polyarthritis that can be induced in susceptible Lewis rats by one i.p. injection of an aqueous, sterile suspension of streptococcal cell wall. Interest- 
ingly, F344 rats housed under conventional conditions are resistant to this treatment because commensal bacterial bowel flora induce neonatally a state of tolerance to arthritogenic epitopes in the streptococcal cell wall material. This state of tolerance is maintained throughout life. In contrast, germ-free F344 rats are as susceptible to streptococcal cell wall-induced arthritis, as are Lewis rats. This susceptibility of germ-free F344 rats rapidly disappears if the bowel flora are reconstituted. In contrast, Lewis rats are arthritis-prone even when they have normal bowel flora, because this tolerance is deficient and/or easily broken (van den Broek et al. 1992).

\subsection{Conclusions}

In conclusion, the "old friends hypothesis" seeks to explain the increasing prevalence of many chronic inflammatory disorders as a failure of immunoregulation secondary to decreased exposure to certain microorganisms that have been present throughout our evolutionary history. It is argued that these organisms are effectively part of our physiology, and are recognised as harmless by the innate immune system, which then activates immunoregulatory circuits, including $\mathrm{T}_{\text {reg }}$ and regulatory APCs. The "old friends" consequently act as adjuvants for other antigens such as self, allergens, and gut contents, and so limit chronic inflammatory immunoregulatory disorders. These mechanisms can be revealed by altering the microbial exposure, or by studying the presence of polymorphisms of the innate immune system, since these two factors provide a series of classical gene-environment interactions. An important consequence of this understanding is the fact that the enormous variability of animal models of inflammatory disorders in different laboratories can now be exploited to investigate these gene-environment interactions. Experiments based on these differences, perhaps involving collaborations between laboratories, or the use of gnotobiotic mice reconstituted with one or a few microbial species, can be applied to those animal models where variable microbial exposure is already known to exert a profound influence. 


\section{References}

Alm JS, Sanjeevi CB, Miller EN et al (2002) Atopy in children in relation to BCG vaccination and genetic polymorphisms at SLC11A1 (formerly NRAMP1) and D2S1471. Genes Immun 3:71-77

Arkwright PD, David TJ (2001) Intradermal administration of a killed Mycobacterium vaccae suspension (SRL 172) is associated with improvement in atopic dermatitis in children with moderate-to-severe disease. J Allergy Clin Immunol 107:531-534

Asadullah K, Sterry W, Volk HD (2003) Interleukin-10 therapy; review of a new approach. Pharmacol Rev 55:241-269

Asea A, Rehli M, Kabingu E et al (2002) Novel signal transduction pathway utilized by extracellular HSP70: role of toll-like receptor (TLR) 2 and TLR4. J Biol Chem 277:15028-15034

Bach JF (2002) The effect of infections on susceptibility to autoimmune and allergic diseases. N Engl J Med 347:911-920

Baker BS, Ovigne JM, Powles AV et al (2003) Normal keratinocytes express Toll-like receptors (TLRs) 1, 2 and 5: modulation of TLR expression in chronic plaque psoriasis. Br J Dermatol 148:670-679

Baldini M, Lohman IC, Halonen M et al (1999) A Polymorphism* in the 5' flanking region of the CD14 gene is associated with circulating soluble CD14 levels and with total serum immunoglobulin E. Am J Respir Cell Mol Biol 20:976-983

Belkaid Y, Piccirillo CA, Mendez S et al (2002) CD4+CD25+ regulatory T cells control Leishmania major persistence and immunity. Nature 420: 502-507

Braun-Fahrlander C, Riedler J, Herz U et al (2002) Environmental exposure to endotoxin and its relation to asthma in school-age children. $\mathrm{N}$ Engl $\mathrm{J}$ Med 347:869-877

Breban MA, Moreau MC, Fournier C et al (1993) Influence of the bacterial flora on collagen-induced arthritis in susceptible and resistant strains of rats. Clin Exp Rheumatol 11:61-64

Brunkow ME, Jeffery EW, Hjerrild KA et al (2001) Disruption of a new forkhead/winged-helix protein, scurfin, results in the fatal lymphoproliferative disorder of the scurfy mouse. Nat Genet 27:68-73

Bulut Y, Faure E, Thomas L et al (2002) Chlamydial heat shock protein 60 activates macrophages and endothelial cells through Toll-like receptor 4 and MD2 in a MyD88-dependent pathway. J Immunol 168:1435-1440

Camporota L, Corkhill A, Long H et al (2003) The effects of Mycobacterium vaccae on allergen-induced airway responses in atopic asthma. Eur Respir J 21:287-293

Caramalho I, Lopes-Carvalho T, Ostler D et al (2003) Regulatory T cells selectively express toll-like receptors and are activated by lipopolysaccharide. J Exp Med 197:403-411 
Contractor NV, Bassiri H, Reya T et al (1998) Lymphoid hyperplasia, autoimmunity, and compromised intestinal intraepithelial lymphocyte development in colitis-free gnotobiotic IL-2-deficient mice. J Immunol 160: 385-394

Curry JL, Qin JZ, Bonish B et al (2003) Innate immune-related receptors in normal and psoriatic skin. Arch Pathol Lab Med 127:178-186

Douek IF, Leech NJ, Gillmor HA et al (1999) Children with type-1 diabetes and their unaffected siblings have fewer symptoms of asthma. Lancet 353:1850

Dutronc Y, Porcelli SA (2002) The CD1 family and T cell recognition of lipid antigens. Tissue Antigens 60:337-353

Edinger M, Hoffmann P, Ermann J et al (2003) CD4+CD25+ regulatory T cells preserve graft-versus-tumour activity while inhibiting graft-versushost disease after bone-marrow transplantation. Nat Med 9:1144-1150

Fontenot JD, Gavin MA, Rudensky AY (2003) Foxp3 programs the development and function of $\mathrm{CD} 4(+) \mathrm{CD} 25(+)$ regulatory $\mathrm{T}$ cells. Nat Immunol 4:330-336

Ghoreschi K, Thomas P, Breit S et al (2003) Interleukin-4 therapy of psoriasis induces Th2 responses and improves human autoimmune disease. Nat Med 9:40-46

Groux H, O'Garra A, Bigler M et al (1997) A CD4+ subset inhibits antigenspecific $T$ cell responses and prevents colitis. Nature 389:737-742

Hanngren A, Odham G, Eklund A et al (1987) Tuberculostearic acid in lymph nodes from patients with sarcoidosis. Sarcoidosis 4:101-104

Hansen G, Berry G, DeKruyff RH et al (1999) Allergen-specific Th1 cells fail to counterbalance Th2 cell-induced airway hyperreactivity but cause severe airway inflammation. J Clin Invest 103:175-183

Heldwein KA, Fenton MJ (2002) The role of Toll-like receptors in immunity against mycobacterial infection. Microbes Infect 4:937-944

Hensen P, Asadullah K, Windemuth C et al (2003) Interleukin-10 promoter polymorphism IL10.G and familial early onset psoriasis. Br J Dermatol 149:381-385

Hernandez-Pando R, Aguilar D, Garcia Hernandez ML et al (2003) Pulmonary tuberculosis in Balb/c mice with non-functional IL-4 genes; changes in the inflammatory effects of TNF- $\alpha$ in the regulation of fibrosis. Eur $\mathrm{J}$ Immunol 34:174-183

Hikita I, Yoshioka T, Mizoguchi T et al (2002) Characterization of dermatitis arising spontaneously in DS-Nh mice maintained under conventional conditions: another possible model for atopic dermatitis. J Dermatol Sci 30:142-153

Hori S, Nomura T, Sakaguchi S (2003) Control of regulatory T cell development by the transcription factor Foxp3. Science 299:1057-1061

Jahnsen FL, Moloney ED, Hogan T et al (2001) Rapid dendritic cell recruitment to the bronchial mucosa of patients with atopic asthma in response to local allergen challenge. Thorax 56:823-826 
Jones CA, Holloway JA, Popplewell EJ et al (2002) Reduced soluble CD14 levels in amniotic fluid and breast milk are associated with the subsequent development of atopy, eczema, or both. J Allergy Clin Immunol 109:858-866

Kabesch M, Peters W, Carr D et al (2003) Association between polymorphisms in caspase recruitment domain containing protein 15 and allergy in two German populations. J Allergy Clin Immunol 111:813-817

Kalliomaki M, Isolauri E (2003) Role of intestinal flora in the development of allergy. Curr Opin Allergy Clin Immunol 3:15-20

Kalliomaki M, Salminen S, Arvilommi H et al (2001) Probiotics in primary prevention of atopic disease: a randomised placebo-controlled trial Lancet 357:1076-1079

Karhukorpi J, Ikaheimo I, Karvonen J et al (2002) Promoter region polymorphism of the CD14 gene (C-159T) is not associated with psoriasis vulgaris. Eur J Immunogenet 29:57-60

Kingo K, Koks S, Silm H et al (2003) IL-10 promoter polymorphisms influence disease severity and course in psoriasis. Genes Immun 4:455-457

Kohashi O, Kohashi Y, Takahashi T et al (1985) Reverse effect of gram-positive bacteria vs. gram-negative bacteria on adjuvant-induced arthritis in germfree rats. Microbiol Immunol 29:487-497

Kojima Y, Kinouchi Y, Takahashi S et al (2001) Inflammatory bowel disease is associated with a novel promoter polymorphism of natural resistanceassociated macrophage protein 1 (NRAMP1) gene. Tissue Antigens 58: 379-384.

Kotze MJ, de Villiers JN, Rooney RN et al (2001) Analysis of the NRAMP1 gene implicated in iron transport: association with multiple sclerosis and age effects. Blood Cells Mol Dis 27:44-53

Krug N, Madden J, Redington AE et al (1996) T-cell cytokine profile evaluated at the single cell level in BAL and blood in allergic asthma. Am J Respir Cell Mol Biol 14:319-326

Kukreja A, Maclaren NK (2002) NKT cells and type-1 diabetes and the "hygiene hypothesis" to explain the rising incidence rates. Diabetes Technol Ther 4:323-333

Lammas DA, Casanova JL, Kumararatne DS (2000) Clinical consequences of defects in the IL-12-dependent interferon-gamma (IFN-gamma) pathway. Clin Exp Immunol 121:417-425

Lauener RP, Birchler T, Adamski J et al (2002) Expression of CD14 and Toll-like receptor 2 in farmers' and non-farmers' children. Lancet 360: $465-466$

Lim S, Crawley E, Woo P et al (1998) Haplotype associated with low interleukin-10 production in patients with severe asthma. Lancet 352:113

Lindberg E, Lindquist B, Holmquist L et al (2000) Inflammatory bowel disease in children and adolescents in Sweden, 1984-1995. J Pediatr Gastroenterol Nutr 30:259-264 
Matricardi PM, Rosmini F, Riondino S et al (2000) Exposure to foodborne and orofecal microbes versus airborne viruses in relation to atopy and allergic asthma; epidemiological study. Brit Med J 320:412-417

McIntire JJ, Umetsu SE, Akbari O et al (2001) Identification of Tapr (an airway hyperreactivity regulatory locus) and the linked Tim gene family. Nat Immunol 2:1109-1116

Moudgil KD, Kim E, Yun OJ et al (2001) Environmental modulation of autoimmune arthritis involves the spontaneous microbial induction of $\mathrm{T}$ cell responses to regulatory determinants within heat shock protein 65 . J Immunol 166:4237-4243

Najarian DJ, Gottlieb AB (2003) Connections between psoriasis and Crohn's disease. J Am Acad Dermatol 48:805-821; quiz 822-824

Nickoloff BJ (1999) Skin innate immune system in psoriasis: friend or foe? J Clin Invest 104:1161-1164

O'Neill LA (2002) Toll-like receptor signal transduction and the tailoring of innate immunity: a role for Mal? Trends Immunol 23:296-300

Ogura Y, Bonen DK, Inohara N et al (2001) A frameshift mutation in NOD2 associated with susceptibility to Crohn's disease. Nature 411:603606

Oppmann B, Lesley R, Blom B et al (2000) Novel p19 protein engages IL12 p40 to form a cytokine, IL-23, with biological activities similar as well as distinct from IL-12. Immunity 13:715-725

Pasare C, Medzhitov R (2003) Toll pathway-dependent blockade of CD4+CD25+ T cell-mediated suppression by dendritic cells. Science 299:1033-1036

Penhale WJ, Young PR (1988) The influence of the normal microbial flora on the susceptibility of rats to experimental autoimmune thyroiditis. Clin Exp Immunol 72:288-292

Raby BA, Klimecki WT, Laprise C et al (2002) Polymorphisms in toll-like receptor 4 are not associated with asthma or atopy-related phenotypes. Am J Respir Crit Care Med 166:1449-1456

Rachmilewitz D, Karmeli F, Takabayashi K et al (2002) Immunostimulatory DNA ameliorates experimental and spontaneous murine colitis. Gastroenterology 122:1428-1441

Rahman P, Bartlett S, Siannis F et al (2003) CARD15: a pleiotropic autoimmune gene that confers susceptibility to psoriatic arthritis. Am J Hum Genet 73:677-681

Rath HC (2002) Role of commensal bacteria in chronic experimental colitis: lessons from the HLA-B27 transgenic rat. Pathobiology 70:131-138

Re F, Strominger JL (2001) Toll-like receptor 2 (TLR2) and TLR4 differentially activate human dendritic cells. J Biol Chem 276:37692-37699

Rehakova Z, Capkova J, Stepankova R et al (2000) Germ-free mice do not develop ankylosing enthesopathy, a spontaneous joint disease. Hum Immunol 61:555-558 
Riedler J, Braun-Fahrlander C, Eder W et al (2001) Exposure to farming in early life and development of asthma and allergy: a cross-sectional survey. Lancet 358:1129-1133

Rodriguez MR, Gonzalez-Escribano MF, Aguilar F et al (2002) Association of NRAMP1 promoter gene polymorphism with the susceptibility and radiological severity of rheumatoid arthritis. Tissue Antigens 59:311-315

Rook GA, Brunet LR (2002) Give us this day our daily germs. Biologist (London) 49:145-149

Rook GA, Martinelli R, Brunet LR (2003) Innate immune responses to mycobacteria and the downregulation of atopic responses. Curr Opin Allergy Clin Immunol 3:337-342

Rook GAW (2000) Clean living increases more than atopic disease. Immunology Today 21:249

Rook GAW, Stanford JL (1998) Give us this day our daily germs. Immunol Today 19:113-116

Satoguina J, Mempel M, Larbi J et al (2002) Antigen-specific T regulatory1 cells are associated with immunosuppression in a chronic helminth infection (onchocerciasis). Microbes Infect 4:1291-1300

Sawczenko A, Sandhu BK, Logan RF et al (2001) Prospective survey of childhood inflammatory bowel disease in the British Isles. Lancet 357:1093-1094

Schultz M, Veltkamp C, Dieleman LA et al (2002) Lactobacillus plantarum $299 \mathrm{~V}$ in the treatment and prevention of spontaneous colitis in interleukin-10-deficient mice. Inflammatory Bowel Diseases 8:71-80

Seddon B, Mason D (1999) Regulatory T cells in the control of autoimmunity: the essential role of transforming growth factor beta and interleukin 4 in the prevention of autoimmune thyroiditis in rats by peripheral CD4(+)CD45RC- cells and CD4(+)CD8(-) thymocytes. J Exp Med 189: 279-288

Sengler C, Haider A, Sommerfeld C et al (2003) Evaluation of the CD14 C$159 \mathrm{~T}$ polymorphism in the German Multicenter Allergy Study cohort. Clin Exp Allergy 33:166-169

Sepp E, Julge K, Vasar M et al (1997) Intestinal microflora of Estonian and Swedish infants. Acta Paediatr 86:956-961

Smit JJ, Van Loveren H, Hoekstra MO et al (2003) Influence of the macrophage bacterial resistance gene Nramp1 (Slc11a1) on the induction of allergic asthma in the mouse. FASEB J 17:958-960

Stanford JL, Nye PM, Rook GA et al (1981) A preliminary investigation of the responsiveness or otherwise of patients and staff of a leprosy hospital to groups of shared or species antigens of mycobacteria. Lepr Rev 52: 321-327

Steel C, Nutman TB (2003) CTLA-4 in filarial infections: implications for a role in diminished T cell reactivity. J Immunol 170:1930-1938

Stene LC, Nafstad P (2001) Relation between occurrence of type 1 diabetes and asthma. Lancet 357:607 
Strachan DP, Taylor EM, Carpenter RG (1996) Family structure, neonatal infection, and hay fever in adolescence. Arch Dis Child 74:422-426

Sudo N, Sawamura S, Tanaka K et al (1997) The requirement of intestinal bacterial flora for the development of an IgE production system fully susceptible to oral tolerance induction. J Immunol 159:1739-1754

Sudo N, Yu XN, Aiba Y et al (2002) An oral introduction of intestinal bacteria prevents the development of a long-term Th2-skewed immunological memory induced by neonatal antibiotic treatment in mice. Clin Exp Allergy 32:1112-1116

Taurog JD, Richardson JA, Croft JT et al (1994) The germfree state prevents development of gut and joint inflammatory disease in HLA-B27 transgenic rats. J Exp Med 180:2359-2364

Thompson SJ, Elson CJ (1993) Susceptibility to pristane-induced arthritis is altered with changes in bowel flora. Immunol Lett 36:227-231

Tomita K, Lim S, Hanazawa T et al (2002) Attenuated production of intracellular IL-10 and IL-12 in monocytes from patients with severe asthma. Clin Immunol 102:258-266

Tremlett HL, Evans J, Wiles CM et al (2002) Asthma and multiple sclerosis: an inverse association in a case-control general practice population. Qjm 95:753-756

Umetsu DT, McIntire JJ, Akbari O et al (2002) Asthma: an epidemic of dysregulated immunity. Nat Immunol 3:715-720

van de Langerijt AG, van Lent PL, Hermus AR et al (1994) Susceptibility to adjuvant arthritis: relative importance of adrenal activity and bacterial flora. Clin Exp Immunol 97:33-38

van den Biggelaar AH, van Ree R, Rodrigues LC et al (2000) Decreased atopy in children infected with Schistosoma haematobium: a role for parasite-induced interleukin-10. Lancet 356:1723-1727

van den Broek MF, van Bruggen MC, Koopman JP et al (1992) Gut flora induces and maintains resistance against streptococcal cell wall-induced arthritis in F344 rats. Clin Exp Immunol 88:313-317

Van der Kleij D, Latz E, Brouwers JF et al (2002) A novel host-parasite lipid cross-talk. Schistosomal lyso-phosphatidylserine activates Toll-like receptor 2 and affects immune polarization. J Biol Chem 277:4812248129

Van der Kleij D, Van Remoortere A, Schuitemaker JH et al (2002) Triggering of innate immune responses by schistosome egg glycolipids and their carbohydrate epitope GalNAc beta 1-4(Fuc alpha 1-2Fuc alpha 1-3) GlcNAc. J Infect Dis 185:531-539

Van Eden W, Koets A, van Kooten P et al (2003) Immunopotentiating heat shock proteins: negotiators between innate danger and control of autoimmunity. Vaccine 21:897-901

Verdu EF, Bercik P, Cukrowska B et al (2000) Oral administration of antigens from intestinal flora anaerobic bacteria reduces the severity of ex- 
perimental acute colitis in BALB/c mice. Clinical and Experimental Immunology 120:46-50

Vincent MS, Leslie DS, Gumperz JE et al (2002) CD1-dependent dendritic cell instruction. Nat Immunol 3:1163-1168

Watanabe A, Takeuchi M, Nagata M et al (2003) Spontaneous development of dermatitis in DS-Nh mice under specific pathogen-free conditions. Exp Anim 52:77-80

Wildin RS, Ramsdell F, Peake J et al (2001) X-linked neonatal diabetes mellitus, enteropathy and endocrinopathy syndrome is the human equivalent of mouse scurfy. Nat Genet 27:18-20

Yazdanbakhsh M, Kremsner PG, van Ree R (2002) Allergy, Parasites, and the Hygiene Hypothesis. Science 296:490-494

Zuany-Amorim C, Manlius C, Trifilieff A et al (2002) Long-term protective and antigen-specific effect of heat-killed Mycobacterium vaccae in a murine model of allergic pulmonary inflammation. J Immunol 169:14921499

Zuany-Amorim C, Sawicka E, Manlius C et al (2002) Suppression of airway eosinophilia by killed Mycobacterium vaccae-induced allergen-specific regulatory T-cells. Nat Med 8:625-629 